\title{
COMPETITION WITHIN FIRMS
}

\author{
Lisa Bruttel* $\mathcal{E}^{*}$ Simeon Schudy ${ }^{\dagger}$
}

\begin{abstract}
We investigate the role of incentives set by a parent firm for competition among its subsidiaries. In a Cournot experiment, four subsidiaries of the same parent operate in the same market. Parents earn a specific share of the joint profit, and can choose how to distribute the remaining surplus (or loss). Results show that parents allocating profits equally among their subsidiaries reach outcomes close to collusion. However, almost half of the parent firms employ a proportional sharing rule instead. These groups end up with profits around the Cournot level.
\end{abstract}

\section{INTRODUCTION}

When evaluating the competitiveness of a market, cartel authorities assume that subsidiary companies with the same parent do not compete with each other or with their parent. According to U.S. antitrust law, subsidiaries in a single entity pursue the goals of the parent. Subsidiaries in a single entity are thus not legally capable of conspiring with their parent firm ${ }^{1}$ or with each other under section 1 of the Sherman Act, because any conspiracy between firms by definition requires at least two separate firms to be involved. Similarly, antitrust law in the European Union presumes that firms belonging to the same owner always act in the owner's interest. ${ }^{2}$

* Professor, Department of Economics, University of Konstanz, Germany. Email: lisa.bruttel@ uni-konstanz.de.

† Department of Economics, University of Konstanz, Germany. Email: simeon.schudy@unikonstanz.de. We thank Florian Englmaier, Martin Fink, Jochen Glöckner, and participants of seminars in Konstanz (Germany) and Kreuzlingen (Switzerland) and of the GfeW annual meeting 2011 in Nuremberg (Germany) for very helpful suggestions.

1 See Copperweld Corp. v. Independence Tube Corp., 467 U.S. 752, 771 (1984).

2 See AKZO Nobel v. Comm'n of the Eur. Communities, Case C-97/08 P, 2009 E.C.R. I-08237 60 (Sept. 10, 2009) ("In the specific case of a parent company holding $100 \%$ of the capital of a subsidiary which has committed an infringement, there is a simple presumption that the parent company exercises decisive influence over the conduct of its subsidiary."). 
If subsidiaries commit a market infringement, a parent firm will at least have the chance to prove that the subsidiary in fact did act independently. This possibility does not exist in the field of merger control. When judging whether to allow or forbid a merger, cartel authorities must forecast whether the planned merger will lead to a concentration of the market structure. ${ }^{3}$ If the merger is generally considered to reduce competition in that market, it will not be permitted. Authorities assume that firms that are allowed to use their market power will always do so. Firms do not have the option to prove that the merger will not affect competition and that they are planning the merger for other reasons such as efficiency improvements only.

The prediction of perfect cooperation between merged firms seems to be a strong simplification and probably does not match the variety in actual behavior. Legal ownership and actual control may in fact be effectively separable, no matter whether this separation occurs intentionally or by inability of the parent firm to control its subsidiaries. For example, high monitoring costs may impede direct control over subsidiaries by parent firms. Instead of direct control, parent firms may use incentive schemes to coordinate their subsidiaries. We are interested in how such intra-firm incentives evolve and whether these incentives affect competition among subsidiaries. Do endogenously determined incentive schemes eventually lead to collusive behavior among subsidiaries, as presumed by law? In order to answer these questions, we designed a laboratory experiment in which a non-producing parent firm sets intra-firm incentives to coordinate its producing subsidiaries by redistributing profits. ${ }^{4}$ We study the intra-firm coordination problem in an unambiguous way and isolate the effects of endogenously determined incentives: Subsidiaries of a parent firm operate in a Cournot oligopoly excluding other competitors.

We find that almost all parent firms converge to a specific incentive scheme, mainly to one of two simple profit-sharing rules: proportional and equal profit sharing. Subsidiaries operating under equal profit sharing rules are able to collude, whereas subsidiaries operating under proportional profit sharing generate profits close to the Cournot level. Our results show that the prediction of perfect cooperation between subsidiary firms belonging to the same owner might be too restrictive. Only around half of the firms in our experiment collude. The other half of firms instead maintain Cournot competition between their subsidiaries.

${ }^{3}$ Guidelines on the Assessment of Horizontal Mergers Under the Council Regulation on the Control of Concentrations Between Undertakings, 2004 O.J. (C 31) 5, 54 (EC).

4 This hierarchical division of owners (parent firms) and decision-makers (producing subsidiaries) also relates our work to a study on strategic delegation in a Cournot duopoly by Steffen Huck, Wieland Müller \& Hans-Theo Normann, Strategic Delegation in Experimental Markets, 22 INT'L J. INDUS. ORG. 561 (2004). 
Our article contributes to the discussion in the literature on what constitutes a single entity. Since the Copperweld case, ${ }^{5}$ there have been many attempts of firm agglomerates to be declared as a single entity, because this legalizes otherwise forbidden agreements between them. Some of them were successful in receiving the desired declaration as a single entity even though they were not under perfectly concentrated ownership and control. ${ }^{6}$ Prominent examples for disputed decisions are litigations involving sports leagues, where the joint marketing of the intellectual properties of the different teams was only sometimes considered not to be conspiratorial according to section 1 of the Sherman Act, because the "sum" of teams could be considered a single entity (see American Needle v. National Football League). ${ }^{7}$ Our article adds to the discussion on the definition of a single entity in two ways. First, our experiment illustrates that, not only the formal ownership and control structure of the firm agglomerate determines their coordinated action, but also the implicit, non-written incentives set by the parent firm through ex-post redistribution. Second, we provide a flexible experimental tool suitable to compare behavior under different incentive systems. This may support judgment in future cases on whether a specific agglomerate of firms constitutes a single entity or not.

The use of the Cournot game in our experiment relates our study to research on group decision making in experimental Cournot oligopolies by Philippe Raab and Burkard Schipper. ${ }^{8}$ While focusing on the comparison of individual decisions and the decisions of groups, the authors also contrasted treatments with different exogenously determined incentive schemes (profit sharing rules) within firms. Raab and Schipper found no significant differences in production quantities of firms under the different incentive schemes. ${ }^{9}$ However, this result was obtained by implementing an additional effort cost in the proportional sharing treatment but not in the treatments with equal profit sharing. The introduction of additional costs was necessary in order to maintain the same theoretical predictions for individual and group treatments, but it makes the comparison of intra-firm incentives

5 See Copperweld, 467 U.S. 752.

${ }^{6}$ See Dean V. Williamson, Organization, Control, and the Single Entity Defense in Antitrust, 5 J. COMPETition L. \& ECON. 723 (2009). Williamson provides a comprehensive overview of the decisions of courts and classifies them in a two-stage single entity test. Broadly speaking, the firm agglomerate cannot only be categorized as a single entity when there is in fact concentrated ownership and control, but also when the court comes to the conclusion that the firms are not potential competitors, for example, because they contribute complementary inputs.

7130 S. Ct. 2201 (2010). See also Marc Edelman, Why the 'Single Entity' Defense Can Never Apply to NFL Clubs: A Primer on Property Rights Theory in Professional Sports, 18 FORDHAM INTELl. PROP., MEdia \& ENT. L.J. 891 (2008).

8 Philippe Raab \& Burkard C. Schipper, Cournot Competition Between Teams: An Experimental Study, 72 J. ECON. BeHAv. \& ORG. 691 (2009).

${ }^{9}$ Id. 
difficult. We suppose that proportional sharing should generally yield higher production quantities in a Cournot game, but additional effort costs (born individually) may induce risk-averse subjects to choose lower production quantities under proportional sharing than under equal profit sharing. Further, the weak treatment differences in Raab's and Schipper's study ${ }^{10}$ may also have resulted from the use of an option in subjects' profit calculators that allowed the automatic calculation of the best response. Till Requate and Israel Waichman have recently shown that the addition of a best-response option to the profit calculator tends to increase the aggregate output to the Cournot level, the level of production observed by Raab and Schipper in both treatments. ${ }^{11}$ In our experiment, the individual's cost structure does not vary with the implemented profit sharing rule, and no best-response option is provided in the profit calculator. Also, we let parent firms decide on the distribution of profits among their subsidiaries instead of exogenously manipulating the profit sharing rule. This allows us to study the endogenous evolution of intra-firm incentives when the firm's subsidiaries compete in the same market.

Intra-firm incentives have also been studied in Bertrand oligopoly experiments. Gary Bornstein and Uri Gneezy ${ }^{12}$ and Bornstein, Tamar Kugler, David Budescu, and Reinhard Selten ${ }^{13}$ have underlined the suggestion that intra-firm incentives matter for coordination within firms as well as for coordination among different firms in the same market. They have found that incentives within the firm matter for the dynamics of prices in Bertrand duopolies. The specific structure of their game reverses the effects of equal and proportional profit sharing compared with Cournot games. Proportional profit sharing in their context means an allocation according to subsidiaries' own asking prices (the prices of intermediate products that add up to the total price of the final product). Sharing in proportion to asking prices thus creates a free-rider problem within the firm, which tends to increase market prices over time. This is in contrast to the effect of proportional sharing in the Cournot case that we consider, in which proportional sharing leads to higher production quantities (and thus to a lower market price).

The remainder of this article is organized as follows. In Part II, we introduce the experimental design and briefly discuss the theoretical benchmark solutions of this framework. Part III presents the results of the experiment, and Part IV concludes.

$10 I d$.

11 Till Requate \& Israel Waichman, A Profit Table or a Profit Calculator? A Note on the Design of Cournot Oligopoly Experiments, 14 ExPERIMENTAL ECON. 36 (2011).

12 Gary Bornstein \& Uri Gneezy, Price Competition Between Teams, 5 Experimental Econ. 29 (2002).

13 Gary Bornstein, Tamar Kugler, David V. Budescu \& Reinhard Selten, Repeated Price Competition Between Individuals and Between Teams, 66 J. ECON. BEHAV. \& ORG. 808 (2008). 


\section{DESIGN AND PROCEDURES}

\section{A. Design}

We study a linear symmetric Cournot oligopoly market in which four subsidiaries of the same parent firm operate. From the study of Steffen Huck, Hans-Theo Normann, and Jörg Oechssler, we know that experimental Cournot oligopolies with four firms competing against each other are never fully collusive but produce aggregate quantities at or above the Cournot outcome. ${ }^{14}$ We consider whether and to what extent such markets become collusive if the Cournot firms do not operate independently but are governed by a parent firm. In our experiment, this parent firm is not involved in production. Its task is to decide after each round about the distribution of the group profit among the four subsidiaries. The parent firm has an incentive to maximize the joint profit of the four subsidiaries, because it receives a predetermined fixed share (20 percent) of the group profit. Our design focuses on the evolution of incentives within the firm and how intra-firm incentives affect coordination among subsidiaries. In order to exclude any confounding effects from market competition, no firms other than the four subsidiaries operate in the market. ${ }^{15}$

Market demand in the experiment was simulated according to the function $P=\max (100-Q, 0)$, where $P$ denotes the market price and $Q$ the total quantity produced by the four subsidiaries (that is, $Q=\Sigma q_{i}$, with $q_{i}$ denoting the quantity produced by subsidiary $i)$. Total production costs were equal to $C=\Sigma c\left(q_{i}\right)$. The instructions ${ }^{16}$ provided subjects with verbal information about demand and cost conditions. Additionally, we offered a "profit calculator" on their computer screens at the beginning of each round, which allowed all subjects to calculate how changes in individual quantities affected profits.

The experiment consisted of 25 rounds. At the beginning of the experiment, five subjects were randomly matched to form a group. One of the five was randomly selected to be the parent firm. Group composition and roles remained the same until the end of the experiment. We used a partner matching procedure to study the evolution of incentives within the firm and the corresponding changes of profits over time.

We structured each round in three stages: a production stage, a redistribution stage, and a summary stage. In the production stage, each subsidiary chose a production quantity. We approximated a continuous action space for subsidiaries by allowing for one decimal point when entering quantities between 0 and 100. The production costs for each subsidiary was $c\left(q_{i}\right)=q_{i}$

${ }^{14}$ Steffen Huck, Hans-Theo Normann \& Jörg Oechssler, Two Are Few and Four Are Many: Number Effects in Experimental Oligopolies, 53 J. ECON. BEHAV. \& ORG. 435 (2004).

15 Examples for such a market structure can be found in the real world, for instance, in major sports leagues such as Major League Soccer (MLS). See also Edelman, supra note 7.

${ }^{16}$ For an English translation of the instructions, see the Appendix. 
and, consequently, the profit generated by a subsidiary was equal to $\pi_{i}=$ $(P(Q)-1) q_{i}$. Note that, because the parent firm could redistribute the sum of profits of the four subsidiaries at the end of each round, costs were not necessarily being born privately by the subsidiaries. Further note that overproduction (such that $Q>99$ ) could lead to a loss. When the loss occurred within the first rounds, subjects' show-up fees were converted into points (1000 points $=1$ euro $)$ and automatically invested to cover the loss. In later rounds, profits from past periods covered losses.

In the redistribution stage, parent firms saw the profits (or losses) generated by each subsidiary and the total quantity produced. Of total profit (or loss), 20 percent was automatically transferred to the parent. Parents then decided freely on how to assign the remaining 80 percent to the subsidiaries (that is, parent firms could redistribute but could not increase profits of specific subsidiaries by creating "new" losses for other subsidiaries).

In the summary stage, all subjects saw the subsidiaries' individually generated profits and the details of the redistribution decision of the parent firm. After the summary stage, the next round started immediately. The whole procedure was common knowledge.

\section{B. Procedures}

We conducted all four sessions at the LakeLab (at the University of Konstanz, Germany). The experiment took place in June and July of 2010. Twenty participants participated in each session; thus, we had a total of 80 participants. Each participant sat at a randomly assigned and separated PC terminal and was given a copy of instructions. A set of control questions was provided on-screen to ensure the understanding of the game. If any participant answered incorrectly, the experimenter provided an oral explanation to the participant. No form of communication between participants was allowed during the experiment.

Participants received a show-up fee of $€ 2$ (equal to $\$ 2.50$ at that time). The experiment took about one hour and 30 minutes, and average income was about $€ 13.40$ (\$16.75). The experiment was programmed and conducted using $z$-Tree. ${ }^{17}$ We recruited participants using the online recruiting system ORSEE. ${ }^{18}$ Participants were part of the LakeLab subject pool, consisting of undergraduate and graduate students of all fields of study.

${ }^{17}$ Urs Fischbacher, z-Tree: Zurich Toolbox for Ready-made Economic Experiments, 10 EXPERIMENTAL ECON. 171 (2007).

18 Ben Greiner, An Online Recruitment System for Economic Experiments, in FoRsCHUNG UND Wissenschaftliches ReCHNEN GWDG BeRICHT 63, 79 (Kurt Kremer \& Volker Macho eds., Göttingen 2004). 
Table 1. Theoretical benchmarks with $\mathrm{n}=4$

\begin{tabular}{llc}
\hline & Total Quantity & Group Profit \\
\hline Collusion & 49.5 & 2450.25 \\
Cournot-Nash & 79.2 & 1568.16 \\
Perfect Competition & 99 & 0 \\
\hline
\end{tabular}

\section{Theoretical Benchmarks and Behavioral Predictions}

The symmetric Cournot Nash equilibrium for the experimental markets is characterized by an individual equilibrium output of $q_{i}^{N}=99 /(n+1)$ and an individual equilibrium profit of $\pi_{i}^{N}=\left(q_{i}^{N}\right)^{2}$. The total Cournot equilibrium output in this case is $Q^{N}=99 n /(n+1)$, and industry profit is given by $\pi^{N}=$ $n\left(q_{i}^{N}\right)^{2}$. Other benchmark outcomes are the collusive case with $Q^{C}=99 / 2$ and the rivalistic (competitive) outcome with $Q^{R}=99$. Table 1 summarizes the numerical values of these benchmarks for $n=4$ subsidiary firms.

Actual quantity choices in the experiment may depend on which profit sharing rule parent firms employ. As parent firms have an incentive to maximize total profit, we expect that they will use ex-post redistribution as an instrument to coordinate quantity choices of their subsidiaries. In order to maximize the joint profits, redistribution must fulfill two conditions. First, it must be systematic, in the sense that subsidiaries can predict from past experience how future redistribution will depend on their quantity choices. Eventual coordination can only be successful if the parent firm's past allocations predict future allocations and if subsidiaries have the beliefs accordingly. As redistribution is the only means of communication for the parent firm, we expect that (after some initial unsystematic trials) parent firms will persistently use one specific profit sharing rule. A first step in our analysis of behavior will be finding out whether there is convergence to such systematic behavior. Second, a systematic redistribution by the parent firm must create appropriate incentives to coordinate the subsidiaries. Parent firms can communicate their agreement or disagreement with certain quantity choices by punishing or rewarding subsidiaries when reallocating profits. ${ }^{19}$

There are two particularly prominent sharing rules that we expect to observe predominantly: proportional and equal profit sharing. Given the appealing fairness of the allocation rule, "everybody gets back what he or

19 Incentives set by the parent firms can also be interpreted as indirect communication between the parent firm and its subsidiaries. For an experiment on the effect of direct communication between firms on collusion, see Ola Andersson \& Erik Wengström, Do Antitrust Laws Facilitate Collusion? Experimental Evidence on Costly Communication in Duopolies, 109 SCANDinavian J. ECon. 321 (2007). See also Miguel A. Fonseca \& Hans-Theo Normann, Explicit vs. Tacit Collusion - The Impact of Communication in Oligopoly Experiments (Working Paper, 2011), available at http://ssrn.com/abstract=1937803. 
she contributed to the joint profit of the group," we expect that some parent firms will implement proportional sharing rules, which reward high contributions to the joint profit with a high share. ${ }^{20}$ Ongoing redistribution proportional to contributed profits gives all subsidiaries the same incentives as firms in a Cournot oligopoly and will therefore induce quantities close to the Cournot equilibrium.

Parent firms who understand the detrimental effect of proportional profit sharing will seek allocation rules avoiding this effect. Maximization of the joint profit can be reached with any allocation rule that positively relates the individually assigned shares to the industry profit but not to the contributed profit share. The simplest example for such an allocation rule (and therefore the one we will focus on in the following analysis) is an equal sharing of profits, such that each subsidiary receives 20 percent of the joint profit. The relation of the assigned share to the contributed share could also be uncorrelated, which we expect to be rare because such rules may lead to confusion among subsidiaries or induce envy among them. When parent firms face excessive competition among their subsidiaries they may also use an anti-proportional sharing rule, which punishes firms with high production quantities and rewards firms with low production quantities. Continuing anti-proportional allocation, however, would make quantities converge to zero, which leads us to expect rare use of this rule in exceptional cases of dramatic overproduction only. Equal sharing, in contrast, sets total profit-maximizing incentives independent of the current quantities.

To summarize, different incentives require different levels of reasoning. ${ }^{21}$ A rule that yields "correct" incentives requires more cognitive effort or ability from the parent firm than just giving back what a subsidiary contributed to the joint profit. As we expect that cognitive effort and ability to vary across subjects, we predict convergence to different sharing rules. We expect equal sharing rules to lead to collusion and proportional profit sharing to foster competition among the subsidiaries.

\section{RESULTS}

Average profits provide a first descriptive insight as to whether parent firms in our experiment are able to make their subsidiaries optimize profits jointly.

20 Pedro Rey-Biel, Inequity Aversion and Team Incentives, 110 SCANDINAVIAN J. Econ. 297 (2008) shows that relative rewards can be used by parent firms to provide effort incentives to inequity-averse subsidiaries. However, this result holds only in a context with individual effort costs born by the subsidiaries. In our design, in contrast, it has a detrimental effect on total profit.

21 See also Benito Arruñada \& Marco Casari, How Enforcement Institutions Affect Markets (Working Paper, 2007), available at http://papers.ssrn.com/sol3/papers.cfm?abstract_ id $=983557$. 


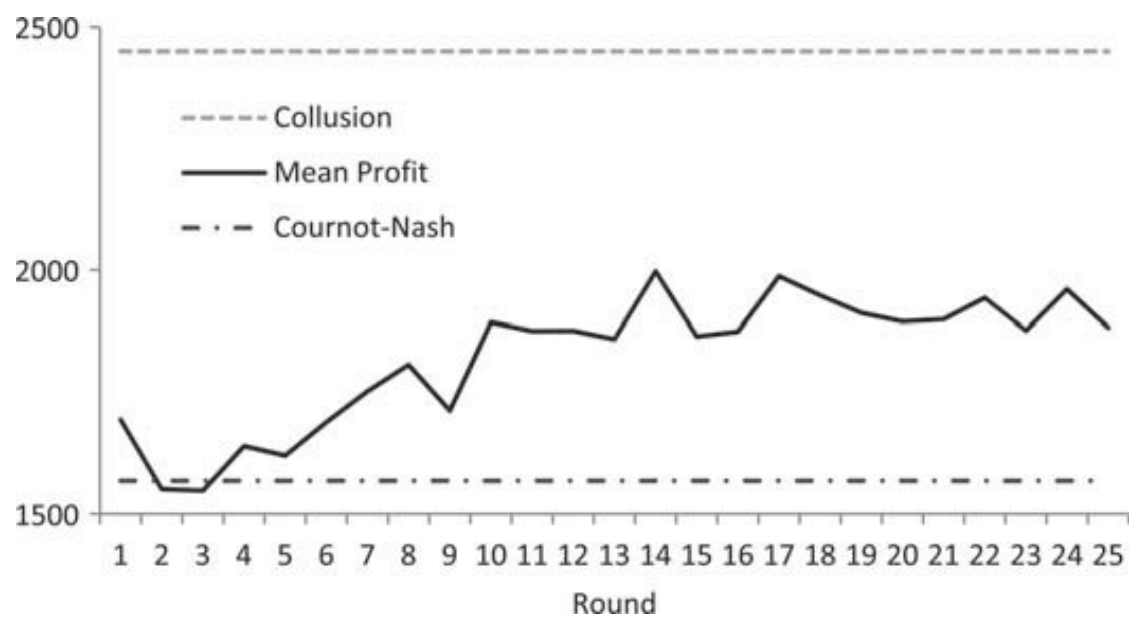

Figure 1. Mean profit over time

Figure 1 illustrates that at an aggregate level, firms do not achieve collusion. We observe 10 out of 16 firms with average profits closer to the Cournot than the collusive level and only 6 with average profits closer to the collusive level. We can thus reject the hypothesis of perfect collusion among subsidiaries of the same parent firm in our experiment (based on a Binomial test, with a $p$-value $<0.01) .^{22}$ We obtain Result 1 .

Result 1. There is competition among subsidiaries of the same parent.

Coordination failure between the subsidiary firms can have two main reasons. Either the parent firm sets incorrect incentives or the subsidiaries do not respond to correct incentives accordingly. We cluster redistribution rules employed by the parent firms (and therefore the incentives set by them) into two broad categories. "Correct" incentives imply a sharing rule that gives subsidiaries incentives to maximize joint profits-for example, equal profit sharing. ${ }^{23}$ "Incorrect" incentives, in contrast, are set with any sharing rule that rewards a high contributed profit with a higher assigned profit share when the total production quantity exceeds the optimal level (49.5) or rules that induce lower production quantities when total quantity lies below the optimum. We concentrate on the first case, because in all groups, quantities (if at all) converge from above the collusive level. To classify the actual sharing rules employed by our parent firms into "correct" and "incorrect" incentives, we judge the distance to a specific sharing rule in the following way. In each round, we calculate the sum of differences in

22 For this test, we used 95-percent collusion as the benchmark, allowing for 5-percent decision errors. However, a $p$-value $<0.01$ still holds as long as one expects at least more than 71 percent of subsidiaries to be closer to the collusive level than to the Cournot level.

23 In one of the groups, the parent firm did not allocate profits equally in every round but took turns in giving the whole group profit to one of the subsidiaries in cyclical order. We treat this rule as "correct" or equal sharing as well. 
percentage points of the actual share each firm receives to the point prediction of the equal (DiffE) and proportional (DiffP) sharing rule:

$$
\begin{gathered}
\operatorname{DiffP}_{i}=\Sigma_{j}\left|b_{j}-a_{j}\right|, \text { and } \\
\operatorname{DiffE}_{i}=\Sigma_{j}\left|0.25-a_{j}\right|,
\end{gathered}
$$

where $i=$ parent $_{i}$ and $j=$ subsidiary $_{j}, a_{j}=$ assigned profit share, $b_{j}=\frac{q_{j}}{Q}, q_{j}=$ quantity produced by subsidiary, $y_{j}$, and $Q=$ total quantity produced by the four subsidiaries. ${ }^{24}$

In a next step, we compare for each round and each parent firm which of the two values DiffE and DiffP is smaller. Taking the average over all rounds, we derive for each parent firm a measure of whether its redistribution scheme is on average over all rounds "closer to" an equal or a proportional sharing rule. This gives us a first, broad measure for different profit sharing rules. Next, we relate the relative closeness to one of the two sharing rules to the average industry profits realized by the firms. Table 2 shows that average industry profits of parent firms employing the equal sharing rule in more than 50 percent of their decisions are in significantly more cases closer to the cartel level than profits by firms employing the proportional sharing rule in more than 50 percent of their decisions (based on a Fisher exact test, with a $p$-value $<0.05$ ).

Result 2. Average profits of firms employing a proportional sharing rule are always below the collusive level. Profits close to the collusive level are only attained by firms employing sharing rules close to equal sharing.

Table 2. Sharing rules and industry profits of groups

\begin{tabular}{llll}
\hline & \multicolumn{2}{l}{ Industry profit closer to } \\
\cline { 3 - 4 } & & Cartel & Cournot \\
\hline Sharing rule closer to & Equal & 6 & 4 \\
& Proportional & 0 & 6 \\
\hline
\end{tabular}

Learning within sessions might bring all groups to combined profit maximization outcomes sooner or later. Figure 1 illustrates that mean industry profits are higher in the second half of the game than profits in the first rounds. We now turn to the question of whether it is convergence to specific rules that eventually leads to higher profits. To find out whether certain groups converge to the equal sharing rule, we run 16 independent regressions (one for each group) to see whether the distance of the actual to the

${ }^{24}$ Note that the two sharing rules make the same prediction when all subsidiaries produce exactly the same amount. However, we rarely observe this case. Differences between minimum and maximum quantities are smaller than two units for only 1.5 percent of our observations. 
equal sharing rule DiffE decreases over time. With $\operatorname{DiffE}_{t}=\beta \cdot t+\varepsilon_{t}$, a $\beta$ significantly smaller than zero indicates that the distance of the actual to the equal sharing rule is decreasing over time. In this case, we say that the group is converging to equal sharing. ${ }^{25}$

According to this clustering, we can treat eight groups as converging to equal sharing and six groups as not converging to the equal sharing rule. According to our convergence measure, two remaining groups converge to both rules. ${ }^{26}$ Figure 2 shows the groups' profits over time, separated by the

Convergence to equal sharing

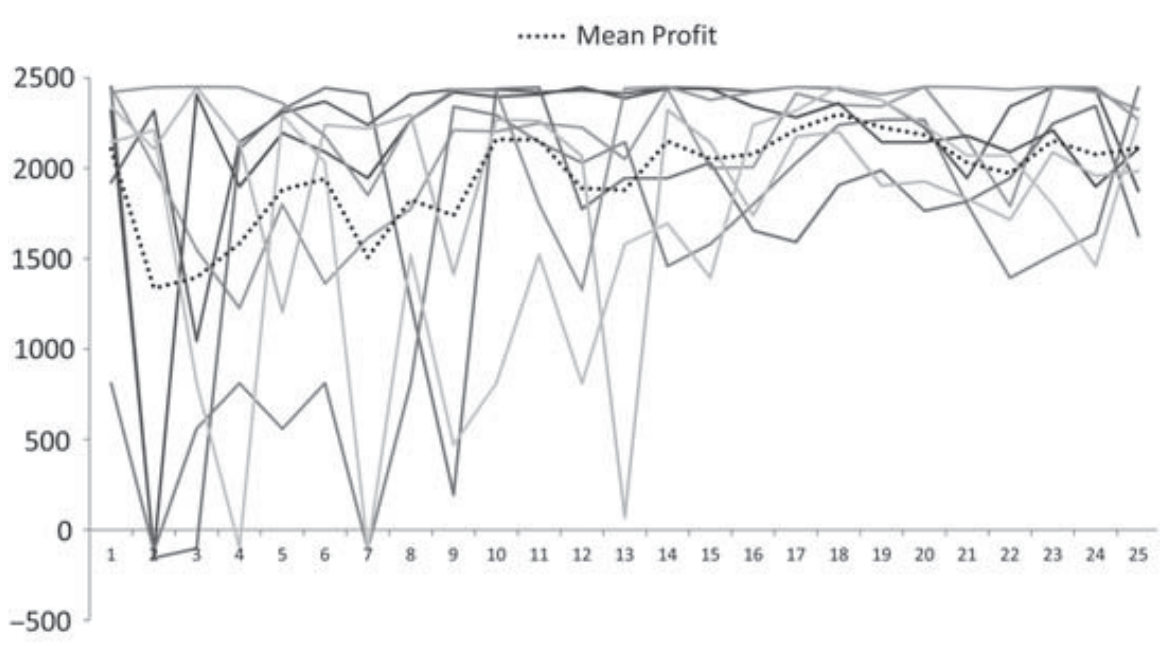

No convergence to equal sharing

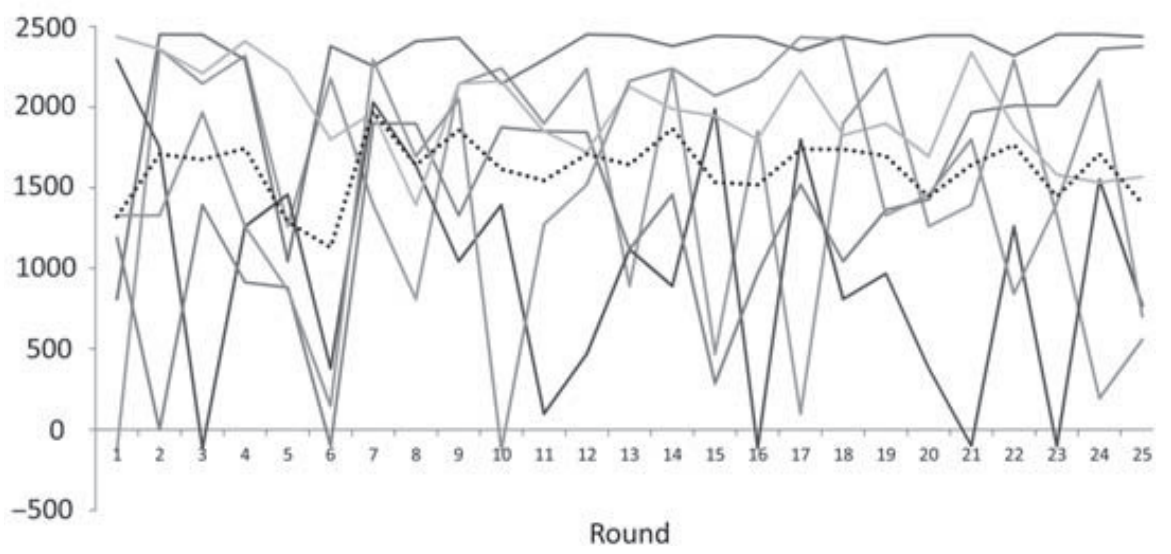

Figure 2. Development of profits over time, grouped by convergence to equal sharing

${ }^{25}$ As convergence (if any) will stop once the profit maximum has been reached, we restrict the convergence analysis to sharing rules in the first 15 rounds of the game. As a robustness check, we also analyzed convergence within the first 10 rounds. Using this criterion, we identify 6 firms that converge to an equal sharing rule. This does not qualitatively change the results reported in Table 3.

${ }^{26}$ The two groups are not contained in Figure 2. The regression results in Table 3 do not qualitatively change if we include these two groups into the cluster of groups converging to equal sharing. 
Table 3. Regression results (OLS): group profit and convergence to the equal sharing rule

\begin{tabular}{llll}
\hline & Not Converging & Converging & $\begin{array}{l}\text { Converging } \\
\text { (incl. group 6 \& 9) }\end{array}$ \\
\hline Round & 1.629 & $23.49^{* * *}$ & $22.75^{* * *}$ \\
& $(8.904)$ & $(6.448)$ & $(5.880)$ \\
Constant & $1,593^{* * *}$ & $1,652^{* * *}$ & $1,652^{* * *}$ \\
& $(133.2)$ & $(116.5)$ & $(104.5)$ \\
Observations & 150 & 200 & 250 \\
R-squared & 0.000 & 0.075 & 0.064 \\
\hline
\end{tabular}

Notes: Robust standard errors are in parentheses; ${ }^{* * *}$ indicates $p<0.01,{ }^{* *} p<0.05,{ }^{*} p<0.1$.

above convergence criterion. The charts indicate that parents converging to an equal profit sharing rule succeed in increasing profits over time, whereas profits of groups with distribution rules not converging to equal sharing follow no time trend. We also regress group profits for the two clusters on the round index. Table 3 shows that profits are significantly increasing over time only for groups converging to an equal sharing rule.

Result 3. Groups with distribution rules converging to an equal sharing rule have increasing profits over time. Profits of groups with distribution rules not converging to equal sharing follow no time trend.

The "closer to" and the convergence measure are relatively broad ones, as they do not account for the absolute distance between the prediction of the (equal or proportional) benchmark and the actual sharing rule. A certain distribution rule might be relatively closer to one of the two rules but far away from the predictions of both rules in absolute terms. To capture the absolute difference between predicted and actual shares, we use an ordinary least squares (OLS) regression explaining current profits with the sharing rule in the previous two rounds. The difference "DiffP - DiffE" denotes the relative closeness to one of the allocation rules. The closer (farther) the sharing rule in a certain round is to equal (from proportional) sharing, the larger is the value of this difference. We therefore expect a positive impact of "DiffP - DiffE" on group profit. "DiffP" and "DiffE" measure the impact of closeness to the two allocation rules separately. We expect that a large difference from equal sharing in $t-1$ (and $t-2$ ) has a negative impact on group profit in round $t$ and that a large difference from proportional sharing has a positive impact on group profit. The regression specifications (1) and (3) include only allocation rules from the previous round, while specifications (2) and (4) take $t-2$ into account as well.

All results point in the expected direction, and most of them are strongly significant, as shown in Table 4. Sharing equally in the previous round increases profits in the current round (note that the negative sign of DiffE 
Table 4. Regression results (OLS): group profit explained by past profit allocation rules

\begin{tabular}{|c|c|c|c|c|}
\hline & \multicolumn{4}{|c|}{ Group Profit in $t$} \\
\hline & (1) & (2) & (3) & (4) \\
\hline DiffP - DiffE in $t-1$ & $\begin{array}{l}848.3^{* * *} \\
(135.7)\end{array}$ & $\begin{array}{l}545.7^{* * *} \\
(170.3)\end{array}$ & & \\
\hline DiffP - DiffE in $t-2$ & & $\begin{array}{l}484.6^{* * *} \\
(145.3)\end{array}$ & & \\
\hline DiffP in $t-1$ & & & $\begin{array}{l}545.0^{* * *} \\
(154.9)\end{array}$ & $\begin{array}{c}309.4 \\
(226.2)\end{array}$ \\
\hline DiffP in $t-2$ & & & & $\begin{array}{l}221.8 \\
(189.0)\end{array}$ \\
\hline DiffE in $t-1$ & & & $\begin{array}{l}-1,170^{* * *} \\
(211.5)\end{array}$ & $\begin{array}{l}-920.9^{* * *} \\
(218.8)\end{array}$ \\
\hline DiffE in $t-2$ & & & & $\begin{array}{l}-750.7^{* * *} \\
(203.6)\end{array}$ \\
\hline Constant & $\begin{array}{l}1,782^{* * *} \\
(35.79)\end{array}$ & $\begin{array}{l}1,779^{* * *} \\
(35.09)\end{array}$ & $\begin{array}{c}1,909^{* * *} \\
(52.21)\end{array}$ & $\begin{array}{l}2,006^{* * *} \\
(50.88)\end{array}$ \\
\hline Observations & 384 & 368 & 384 & 368 \\
\hline R-squared & 0.130 & 0.157 & 0.150 & 0.204 \\
\hline
\end{tabular}

Notes: Robust standard errors are in parentheses; ${ }^{* * *}$ indicates $p<0.01,{ }^{* *} p<0.05,{ }^{*} p<0.1$.

indicates that profits decrease the farther away an observed sharing rule is from equal sharing). Sharing proportionally leads on average to an increase in quantities and thereby reduces profits. The positive effect of equal sharing on profits is stronger than the negative effect of proportional sharing. Furthermore, with proportional sharing, the effect of "DiffP in $t-1$ " is only significant if we do not include $t-2$ in the regression as well. This result indicates that proportional sharing on group profit in round $t-1$ is highly correlated with proportional sharing in $t-2$ (based on Spearman's $\rho=0.68, p$-value $<0.01$ ). With equal sharing, the effect rather accumulates over time. Including "DiffE in $t-2$ " in the regression reduces the impact of "DiffE in $t-1$ " only by a small extent, and the twice-lagged variable is highly significant itself. We conclude with Result 4.

Result 4. The closer the profit allocation is to equal sharing in one round, the higher are group profits in the two following rounds.

\section{CONCLUSION}

We investigated the evolution of incentives set by parent firms for their subsidiaries and their role for competition among subsidiaries in a Cournot oligopoly experiment. We observed most parent firms converging to specific profit redistribution schemes. Parent firms chose simple profit 
sharing rules that created strong incentives for subsidiaries: Most of the parent firms implementing equal profit sharing rules were able to coordinate their subsidiaries to act in the firm's joint interest. When the sharing rule employed by the parent firm was proportional to subsidiaries' contributions to the joint profit, subsidiaries did compete. Furthermore, our data showed that the repeated use of a specific redistribution scheme helps to circumvent the problems caused by lack of commitment. Incentives set by parent firms were in fact decisive for the degree of competition among subsidiaries.

The interpretation of our results depends on the reader's viewpoint. From a regulator's perspective, it is promising that half of the firms in the experiment did not manage to collude, but it is worrying that the other half did. From a coordinating parent firm's perspective, the good and bad news are reversed: It can be considered good news that around half of the firms managed to coordinate even under difficult circumstances. The other half, however, did not manage to coordinate, sometimes even despite the parent firm setting correct incentives for cooperation among the subsidiaries. Accordingly, the implications of our experiment are twofold.

From a regulator's perspective, our experiment recommends taking planned intra-firm incentives into account when investigating whether a planned merger will lead to a concentration of the market structure. In light of our results, the assumption of perfect cooperation between merged firms seems to be a strong simplification. For example, high monitoring costs may impede perfect control over subsidiaries by parent firms. Instead of direct control, parent firms may use incentive schemes to coordinate their subsidiaries. The simple presumption of collusion among subsidiaries of the same parent may then be too restrictive. Instead, the likelihood of concerted action depends on the incentives for the subsidiaries within the merged firm. This relates our study also to the concept of league-based common property systems discussed in Edelman's article. ${ }^{27}$ A prominent example for leaguebased common property systems is the original model for Major League Soccer (MLS). It was designed to serve as a "single entity" league for antitrust advantages by generating common interests of clubs playing in the league. Its incentives were exactly designed such that the league's "subsidiaries" (the clubs) maximize the league's profits instead of individual clubs' profits. However, eventually, the MLS became a mix-mode model because wealthy investors did not want to become "faceless" but own champions, which was not possible in the common property system. ${ }^{28}$

From an organizational behavior perspective, the results illustrate the tradeoff that corporate management faces when deciding on incentive

27 Edelman, supra note 7, at 900-03.

28 It was envisaged that investors own shares of the league entity and centrally set prices for tickets, concessions, broadcasting, and so forth in a board of directors. See also id. at 901-02. 
schemes for the executives of the different divisions. Bonus payments at the executive level typically depend on the division's profit and on the total profit of the company as well. ${ }^{29}$ The organization of divisions as independent profit centers is quite popular, as it allows the parent firm to determine the subsidiaries' individual profitability and reduces monitoring costs. ${ }^{30}$ However, this organizational structure will not provide incentives to maximize the total profit of the company if divisions compete. Our experiment can reproduce this tradeoff at a very stylized level and may therefore serve as a basic design to study the effects of different variants of such combined bonus payment rules in the future.

\section{APPENDIX: TRANSLATED INSTRUCTIONS}

\section{A. General Information}

Today you are taking part in a decision-making experiment. If you read the following instructions carefully, you will be able to earn money. The amount you earn depends on your own and on other participants' decisions.

For the entire duration of the experiment, communication with other participants is not allowed. We therefore ask you not to talk to each other. Breaking this rule leads to exclusion from the experiments and any payoffs.

If you have problems understanding the experiment, please have a second look at the instructions. If you still have questions, please raise your hand. We will come to your cubicle and answer your questions personally. During the experiment, we do not use euros, we use points. The number of points you earn in the experiment is converted into euros with the following exchange rate.

$$
1000 \text { points }=1 \text { euro. }
$$

At the end of the experiment, you will receive all points earned during the experiment converted into euros.

The following pages will explain the experiment in detail. First we explain the general procedure. Then we explain the different decision making screens. Before the experiments starts, control questions will appear on the screen in order to help you to fully understand the procedure. The

${ }^{29}$ For a formal model, see Guido Friebel \& Michael Raith, Resource Allocation and Organizational Form, 2 AM. ECON. J.: MicroeCON. 1 (2010).

30 See also Dilip Mookherjee \& Stefan Reichelstein, Incentives and Coordination in Hierarchies, 1 B.E. J. THEORETICAL ECON. 4 (2001). 
experiment does not start until all participants have solved the control questions and are completely familiar with the course of the experiment.

\section{B. The Experiment}

At the beginning of the experiment you will be randomly matched with 4 other participants. That is, you make decisions in a group of 5 people. Neither you nor other participants learn anything about the identity of the other participants, either during or after the experiment.

The experiment consists of 25 rounds. In each round you interact with the same people. Each participant in your group represents a firm. There are four producing firms (Firms 1 to 4) and one firm (Firm 5), which does not produce but instead decides on the distribution of profits between the five firms in your group. At the beginning of the experiment you see on the screen which firm you represent. You will represent the same firm in all 25 rounds.

Firms 1, 2, 3, and 4 produce the same (virtual) good and sell it on the same market. Production costs per unit are equal to one point. All producing firms decide simultaneously on how many units of the good they produce. There is one important rule: The higher the total quantity produced by the four firms, the lower the market price. If some maximum of total output is reached the price will be equal to zero.

The per unit profit of each producing firm ("generated profit") equals the difference between the market price and the unit cost of production. The "generated profit" (in points) thus equals:

Generated profit of a producing firm $=$

(Market price -1$) \times$ Quantity produced by the firm.

In each round, Firms 1 to 4 decide simultaneously on how many units of the good they will produce. The computer calculates the total quantity produced by the four firms and the corresponding market price. The "generated profit" is not equivalent to payoffs earned by the firms in this round. Firm 5 decides on the actual payoff to each producing firm after the production decision: Firm 5 receives information about the total quantity produced and the profits generated by each firm as well as information about the resulting total profit. Firm 5 automatically receives 20 percent of the total profit. Then, Firm 5 decides on how to distribute the remaining 80 percent of the total profit among Firms 1 to 4 . Firm 5 can freely choose how to distribute the profit among Firms 1 to 4 .

If the total profit is negative, Firm 5 automatically bears 20 percent of the loss and decides on how to distribute the remaining 80 percent of the loss among Firms 1 to 4 (in this case the 2 euros you received for 
participating will be automatically converted into points and used to compensate for the loss).

Importantly, Firm 5 can only redistribute profits or losses from the current round. That is, it is also impossible to transfer a loss to one firm in order to transfer additional profits to another firm.

After Firm 5 has made the distribution choice, all firms receive feedback on the chosen distribution. Then the next round starts. Again Firms 1 to 4 make a production decision and Firm 5 decides on the distribution.

The experiment consists of 25 rounds. After the last round all participants see a summary of their points received in each round on the computer screen. You receive all points received converted into euros.

\section{Procedure on Screen}

Firms 1 to 4 see the following screen (an example screen for Firm 1).

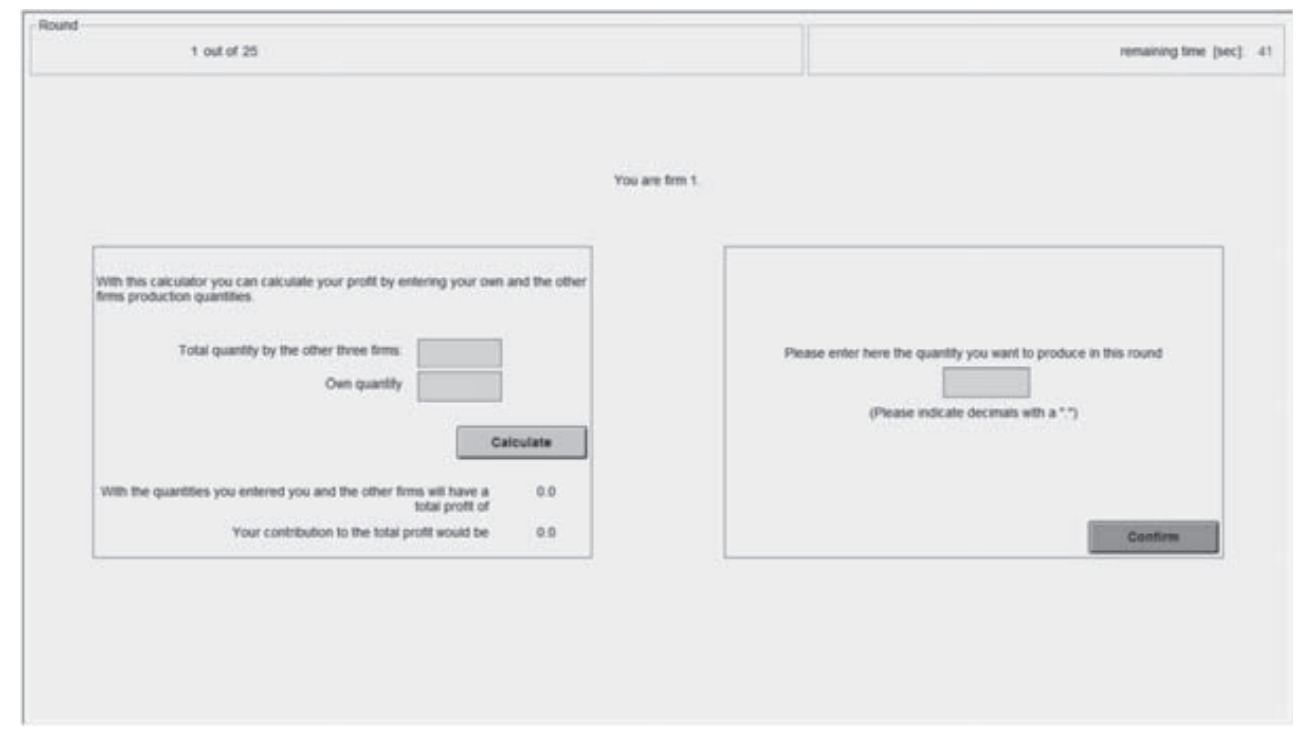

On the left hand side you see a profit calculator. With this calculator you can test how your "generated profit" varies in production quantities. You can try out how the generated profit changes when you change your own production quantity or the total quantity produced by the other three firms. The quantities you enter in the calculator are completely hypothetical. You can use the calculator to receive information on the consequences of your own and others' decisions. You can try as many calculations as you like. When you have decided on how much to produce, enter the amount on the right hand side and click on "confirm." You cannot decide on the production quantity of other firms.

Firm 5 can also use a profit calculator. While Firms 1 to 4 choose their production quantities, Firm 5 can try out how the profits of each firm and 
the total profit vary when production quantities vary. The screen for Firm 5 looks as follows:

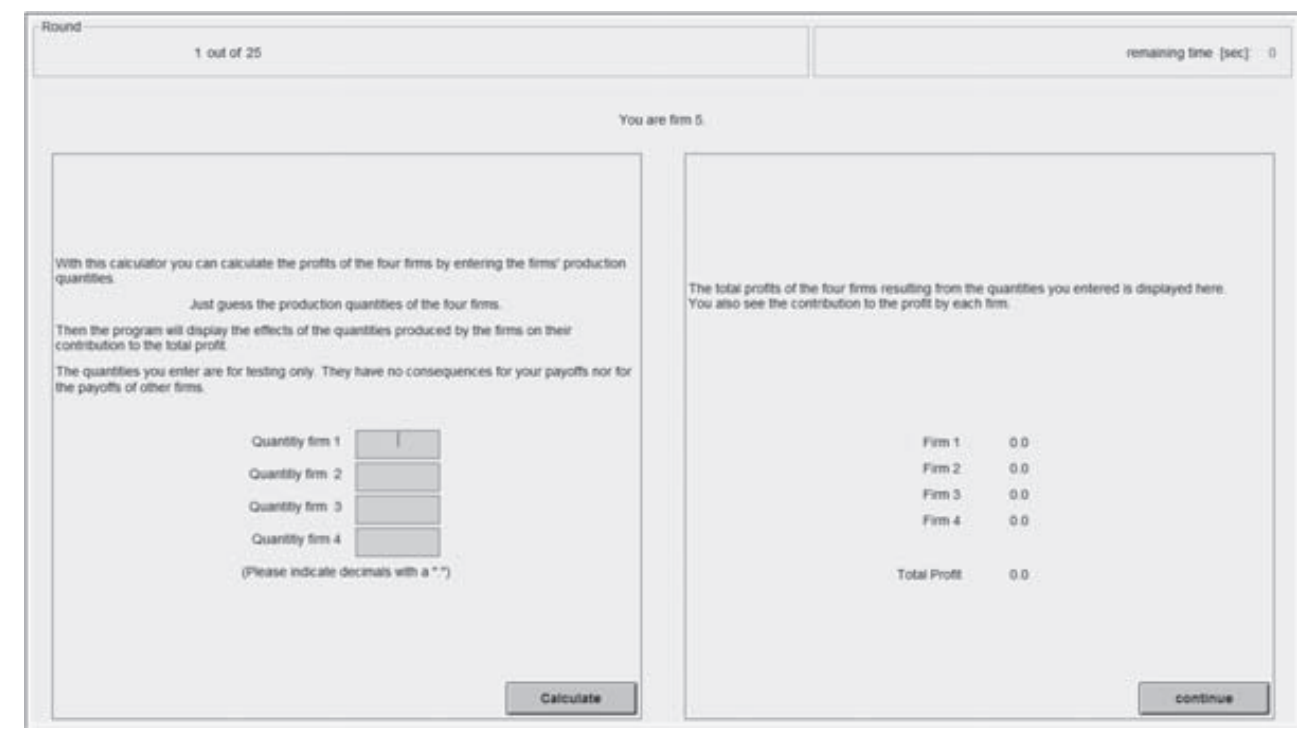

After Firms 1 to 4 have made their production decisions, Firm 5 sees the following screen.

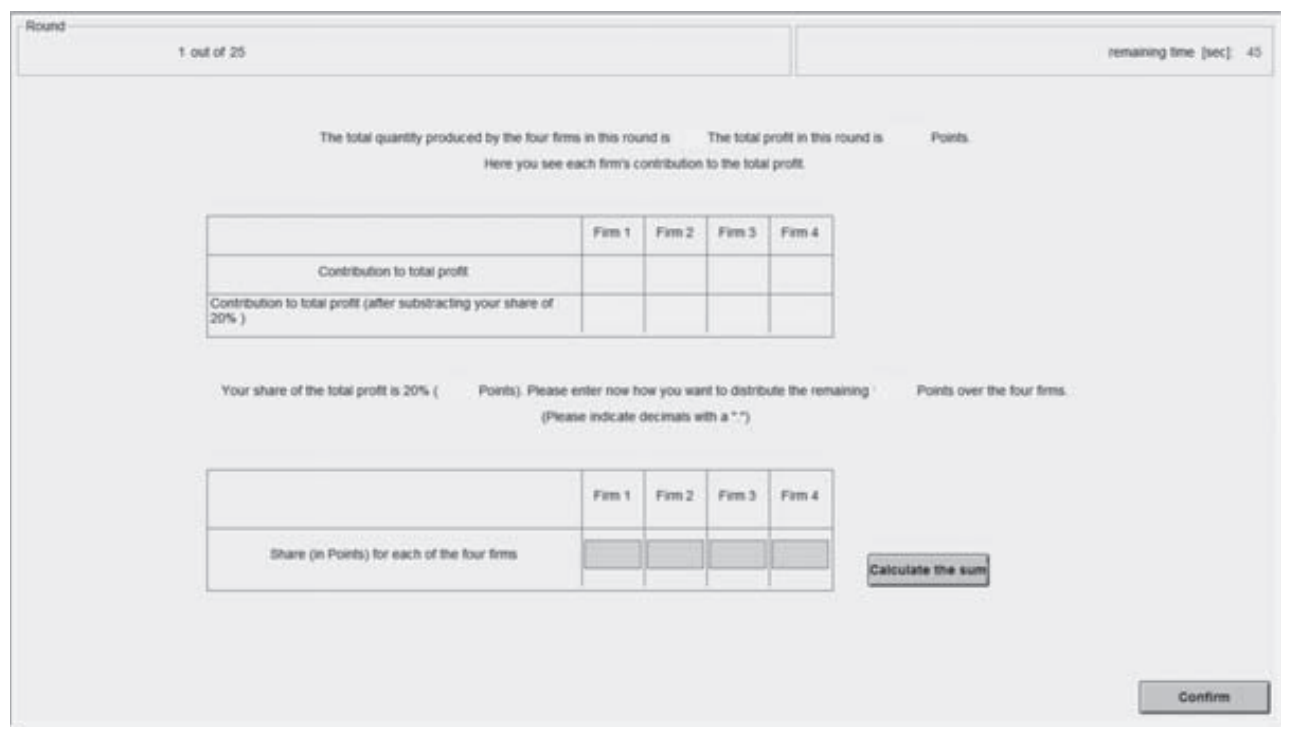

The screen shows the "generated profits" by each producing firm and the "generated profits" after the deduction of the 20 percent for Firm 5. Firm 5 then decides on how many points it will assign to Firms 1 to 4 . In order to do so, Firm 5 enters the number of points for each producing firm in the shaded fields. A click on "calculate the sum" shows the sum of assigned points and the number of points left for distribution. Clicking on "confirm" 
implements the chosen distribution of points. Then all firms see the following screen.

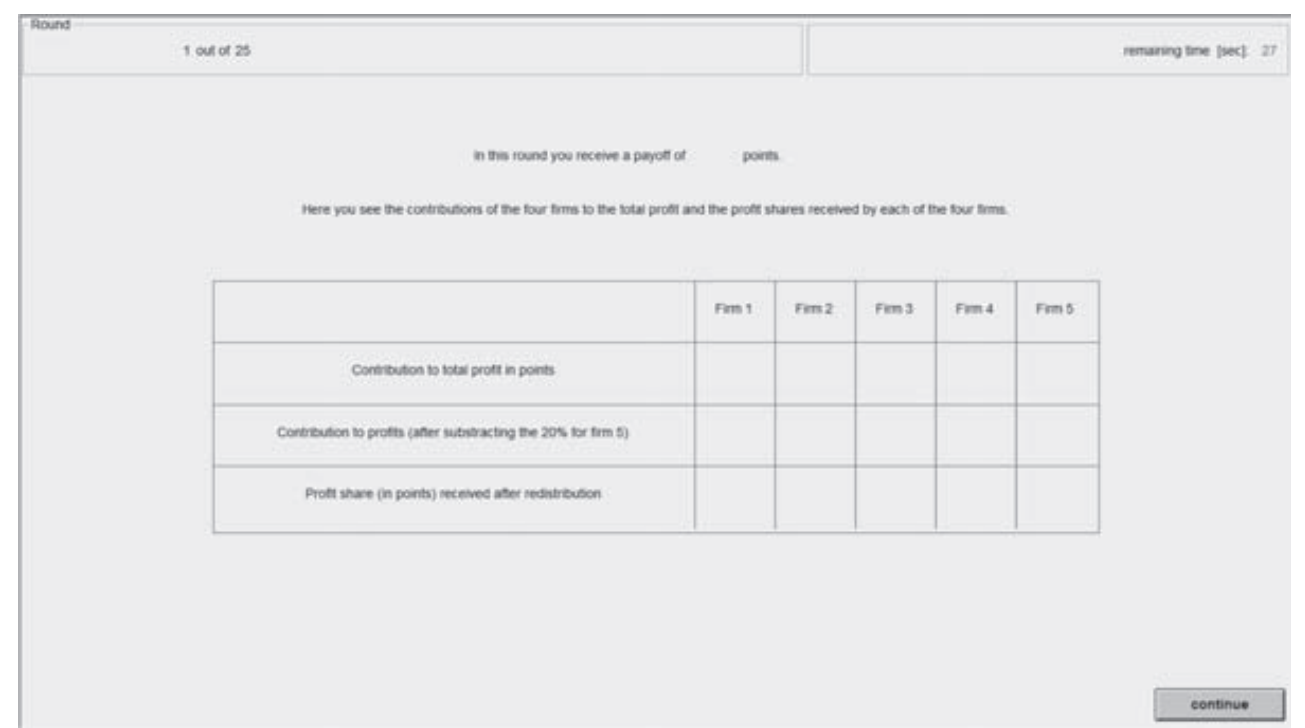

\section{Control Questions}

Please click now on the "continue" button on your computer screen. We will display some control questions on screen. Please answer these questions. The questions only serve for the understanding of the course of the experiment. Your answers do not affect the payoffs received in the experiment.

If you have any questions, please raise your hand. We will come to your cubicle and answer your questions. 